\title{
Value, Access, and Cost of Cancer Care Delivery at Academic Cancer Centers
}

\author{
Elizabeth A. Nardi, MS ; Julie A. Wolfson, MD, MSHS ; Steven T. Rosen, MDc; Robert B. Diasio, MD'; \\ Stanton L. Gerson, MDe; Barbara A. Parker, MD; joseph C. Alvarnas, MDc; Harlan A. Levine, MDc; \\ Yuman Fong, MDc; Dennis D. Weisenburger, MDc; C. Lyn Fitzgerald, MJa; Maggie Egan ${ }^{\mathrm{a}}$; \\ Sharon Stranford, PhD; ; Robert W. Carlson, MD; ; and Edward J. Benz Jr, MD ${ }^{\mathrm{h}}$
}

\begin{abstract}
Key challenges facing the oncology community today include access to appropriate, high quality, patient-centered cancer care; defining and delivering high-value care; and rising costs. The National Comprehensive Cancer Network convened a Work Group composed of NCCN Member Institution cancer center directors and their delegates to examine the challenges of access, high costs, and defining and demonstrating value at the academic cancer centers. The group identified key challenges and possible solutions to addressing these issues. The findings and recommendations of the Work Group were then presented at the Value, Access, and Cost of Cancer Care Policy Summit in September 2015 and multi-stakeholder roundtable panel discussions explored these findings and recommendations along with additional items.
\end{abstract}

J Natl Compr Canc Netw 2016;14(7):837-847

\section{Executive Summary}

Access to appropriate, high-quality, patient-centered cancer care is of vital importance to patients with cancer and their families. Optimally, patients should have access to provider networks that include experienced oncology experts and multidisciplinary cancer centers. Nevertheless, there are challenges to accessing highquality cancer care. One threat to access at academic cancer centers is that of network adequacy, or a health plan's capacity to offer enrollees timely access to an ample number of in-network providers and services; it falls to the centers themselves to educate health care consumers about the need to ensure that such specialized centers are included in their health coverage plans.

Across the oncology community, the mission to define and deliver high-value care has been a key focus

From ational Comprehensive Cancer Network, Fort Washington, Pennsylvania; ' University of Alabama at Birmingham Comprehensive Cancer Center, Birmingham, Alabama; 'City of Hope Comprehensive Cancer Center, Los Angeles, California; 'Mayo Clinic Cancer Center, Rochester,

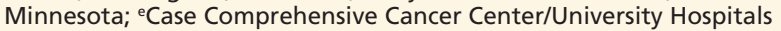
Seidman Cancer Center and Cleveland Clinic Taussig Cancer Institute, Cleveland, Ohio; fUC San Diego Moores Cancer Center, La Jolla, California; gPatient, City of Hope Comprehensive Cancer Center, Los Angeles, California; and hana-Farber Cancer Institute, Boston, Massachusetts. and will continue to lead health reform efforts. In the setting of health care reform, there is a call for shifting to new value-based payment models; value in this vein is often understood to be the balance of the treatment benefit and/or quality of care as weighed against economic costs. Because of the expanded mandates of academic cancer centers that incur higher costs, these centers are often asked to demonstrate the value of the care they provide. High cost can be driven by a range of factors, including drug prices, acute inpatient hospitalizations in the last months of life, or high-cost imaging. The stewards of this highly expensive care include health care providers, payers, health systems, and cancer center administrators, and all can be impacted by increasing health care costs. Payment reform provides additional opportunity for cost control while remain-
Submitted March 16, 2016; accepted for publication May 24, 2016.

Dr. Parker has disclosed that she has received clinical research support from Genentech. Ms. Nardi, Ms. Fitzgerald, and Dr. Carlson are employees of NCCN. The remaining authors have disclosed that they have no financial interests, arrangements, or affiliations with the manufacturers of any products discussed in this article or their competitors.

Correspondence: Elizabeth A. Nardi, BS, NCCN, 275 Commerce Drive, Suite 300, Fort Washington, PA 19473. E-mail: nardi@ncen.org 
Nardi et al

ing focused on quality. Academic cancer centers are criticized for their higher costs of care; meanwhile, they develop novel therapies and diagnostics, train the next generation of health care providers, and often provide highly specialized and resource-intense services to patients that are not otherwise available.

NCCN convened a Work Group composed of NCCN Member Institution cancer center directors and their delegates to examine the challenges of access, high costs, and defining and demonstrating value at the academic cancer centers (see supplemental eAppendix 1, available with this article at JNCCN. org). The group identified key challenges and possible solutions to addressing these issues. The findings and recommendations of the Work Group were then presented at the Value, Access, and Cost of Cancer Care Policy Summit in September 2015, and multistakeholder panel discussions explored these findings and recommendations along with additional items (see supplemental eAppendix 2).

\section{Patient Perspectives}

Two cancer survivors provided the patient perspective on value, access, and cost of care; their experiences were based at the City of Hope Comprehensive Cancer Center as a representative academic cancer center. Although one survivor originally went to City of Hope seeking a second opinion, the other sought care there because she lived in a remote area without access to cancer care locally. They differentiated their experience at City of Hope from what was available at their local community hospitals, noting the importance of (1) specialized oncologists and radiologists; (2) access to researchers and clinical trials; (3) accommodations for out-of-town patients; (4) care coordination; (5) patient navigation; and (6) decision-making and implementation by a complete multidisciplinary team. One patient shared her significant challenges in terms of access; at the time of diagnosis she was covered under a health insurance plan that offered very few choices, which led to delays in approvals for visits and treatment. Ultimately, she was fortunate to change to a broader plan, allowing her to receive care at City of Hope. Another patient shared elements of value for her in her care, including the nature of her relationship with her physician in which she was comfortable asking questions; the same patient felt that clinical trial availability was additionally of great importance. These 2 survivors emphasized the value of selecting an insurance plan that ensures access to care. Both also noted significant out-of-pocket costs, while noting that selection of such an insurance plan can help ease the financial burden. Both survivors provided examples of how individualized perspective on access, value, and cost can be for patients with cancer.

\section{Challenges to Access to Cancer Care}

Access to appropriate cancer care is essential to ensuring high-quality care. Patients should have access to experienced, expert provider networks that include oncologists and multidisciplinary academic cancer centers, especially when the required care is highly specialized and cannot be provided elsewhere. Network adequacy is a key component of health plans. However, significant challenges to accessing high-quality cancer care have developed, including a growing demand for oncology services in the setting of a limited oncology workforce, disparities to receiving care, and increased economic pressures.

With advances in medicine resulting in greater life expectancies, most people living longer have one or more chronic conditions, leading to an increasing demand for oncology services. With factors such as tobacco use and obesity compounding the rise in cancer incidence, US cancer incidence is estimated to increase by $45 \%$ by $2030,{ }^{1}$ accompanied by an increased demand for services. This adds a burden to an already strained workforce, and an inadequate number of trainees are on deck to replace those retiring. Furthermore, an inadequate number of minority oncologists and oncologists in rural settings are poised to address gaps in racial and ethnic disparities in communities or eliminate barriers to care based on distance. Without an increase in providers, the workforce will be unable to fill the escalating demand gap.

Despite advances in outcome with improved screening and treatment, access to these services is not equitable among US racial and ethnic groups. As compared to non-Hispanic Whites, African Americans are $2.5 \%$ more likely to develop cancer and $19.6 \%$ more likely to die from it. ${ }^{1}$ Such disparities can be rooted in a range of causes from diagnosis in later stages, access to care, or tumor biology. Availability to high-quality cancer care services across 
Value, Access, and Cost of Cancer Care

ethnic and racial groups is paramount to closing these gaps.

Economic pressures provide increasing challenges to accessing cancer care, from escalating costs, shifting payment models and insurance exchanges to practice consolidation, and administrative and regulatory burdens. Although access to optimal cancer care requires that it be covered in third-party health plans, insurers have shifted burdens toward patients (higher premiums and out-of-pocket costs), because these costs have increased at unsustainable rates. All angles of the equation are challenged, however, with insurers faced with how to pay for services, employers and individuals faced with rapidly increasing premiums, and providers faced with changes to how they are being reimbursed for services. There is a shift in both public and private insurers from a feefor-service model to alternative models (bundled, episode-based, or value-based payments); examples include Anthem's Cancer Care Quality Program, Centers for Medicare \& Medicaid Services' Oncology Care Model, and UnitedHealth Group's Episode Payment Model. These models often require providers to report on metrics to receive payment. Preauthorization procedures may be burdensome and can restrict access to services, delay timely care, and reduce clinician availability for patient care. A common response to such administrative burdens is practice consolidation, which affects access if providers who were once covered are no longer in network due to mergers/acquisitions. With hospital prices in monopoly markets set $15.3 \%$ higher than those in markets with 4 or more hospitals, data suggest that hospital consolidation drives higher prices for the privately insured. ${ }^{2}$ Some insurers are trying to offset costs through cost-shifting, calling for premium increases. In major cities in 2014, silver marketplace premiums ranged from decreasing by $10.6 \%$ to increasing by $38.4 \% .^{3}$ Moreover, the average plan deductible nearly doubled between 2006 and 2014, ${ }^{4}$ rendering health care unaffordable for some.

The Affordable Care Act (ACA) and its attendant insurance exchanges have expanded access to insurance for millions of Americans through various types of insurers who have seen an influx of insured consumers. However, with increased costs, there is less money to provide services for more insured consumers. As increasing cancer care costs are met with increasing demand, the ACA impact is profoundly felt in oncology. In light of major losses on policies sold on ACA exchanges, UnitedHealth recently announced that they will consider withdrawing from them. ${ }^{5}$ Similarly, the exchange Health Republic Insurance of New York lost nearly $\$ 53$ million in the first 6 months of 2015 and more than $\$ 77$ million in $2014,{ }^{6}$ leading to state regulators removing it from the ACA exchange. ${ }^{7}$ This was the only public health exchange in New York that included Memorial Sloan Kettering Cancer Center in its plan. ${ }^{7}$ However, access to high-quality cancer care requires access to expert specialists and subspecialists who need to be included in coverage plans.

Payers assert that the rising health care costs will lead to rising health care consumerism, with 2014 showing the largest 1-year increase in enrollment in high-deductible consumer-driven health plans (18\% to $23 \%$ of all covered employees). ${ }^{8}$ However, consumers may not be readily aware of the impact to their personal finances because they pay indirectly, with employers and the federal government (via Medicare/Medicaid) fronting the money. ${ }^{9}$ Payers, too, must respond to market changes and movement toward exchanges with consumer selection based on price. With consumers choosing more affordable plans, these less expensive plans offered by payers may not include academic cancer centers that cost more. Payers suggest that these centers focus on the consumer with a commitment to maximizing value for patients, asserting that this requires centers to make data available to exemplify their value.

In response to such influences, insurance companies are also redesigning networks, creating narrow or tiered networks. Narrow networks are defined as plans that limit the number of providers who can participate in order to reduce costs. ${ }^{10}$ Typically such plans offer low monthly premiums, ${ }^{11}$ although consumers can be exposed to significant out-of-pocket costs if they seek or need care outside of the prescribed network, ${ }^{12}$ with fewer providers included than in a typical Health Maintenance Organization. ${ }^{10}$ Tiered networks are less restrictive than narrow networks, and encourage patients to visit preferred providers with tiered cost-sharing requirements based on the provider's position in the network. ${ }^{13}$ With this evolution, the availability of Preferred Provider Organizations (PPO), which offer broad networks and cover some out-of-network costs, is decreasing. Only 33\% of 2015 silver plan PPO offerings remain available 
Nardi et al

in 2016 either because carriers exited the market or they discontinued their PPO plans, ${ }^{14}$ and due to expense, premiums increase faster for PPOs than for other plans. ${ }^{15} \mathrm{With}$ premium increases, PPO disappearance, and unavailability of public health exchanges, consumers can be left with minimal coverage options.

\section{NCl-Designated Cancer Center Experience With Health Care Exchanges}

The challenges faced in accessing cancer care are compounded when patients seek care at academic cancer centers. These centers specialize and subspecialize in cancer, often offering clinical trials not otherwise available. Ensuring access to these centers is of vital importance to ensure optimal, multidisciplinary care of many cancer types. A 2015 survey of NCI-designated cancer centers examined the scope of reportedly narrow networks and health care exchanges. Avalere Health LLC and NCCN sent surveys to $61 \mathrm{NCI}$-designated centers, with responses from 20 centers across 19 states, which indicated regional variability in exchange plan participation.

A total of $75 \%$ of respondents indicated they were covered by at least some of the exchange plans offered by most of the carriers in their state, ${ }^{16}$ whereas $65 \%$ indicated their center was excluded from some networks despite their attempt to be in-network. ${ }^{17} \mathrm{~A}$ total of $30 \%$ opted out of exchange contracts because of low reimbursement rates. ${ }^{17}$ Some reported a lack of interest by the center in contracting with the exchange, with $13 \%$ of these covered by all state exchange plans. ${ }^{17}$ Half of the centers indicated that exchange plans have tiered provider networks and that most of the centers are only in the higher tiers. ${ }^{16}$ These tiers have enrollee cost-sharing components, with more cost shifted to enrollees in higher tiers. However, exchange plan reimbursement rates were above Medicaid and Medicare fee-for-service rates and only slightly below commercial reimbursement rates. Academic medical centers did not seem to be systematically excluded from network participation. ${ }^{17}$ A separate Avalere survey compared commercial and exchange networks, finding that exchange networks had $42 \%$ fewer oncology providers, ${ }^{18}$ and that none of the federal exchange plans in Houston included top-ranked MD Anderson Cancer Center in their networks. ${ }^{15}$ These findings demonstrate a major threat to access at academic cancer centers for patients with cancer who have federal exchange plans. Failure to include centers such as MD Anderson Cancer Cen- ter in networks may limit patient access to life-saving clinical trials or treatment by subspecialists.

With millions of Americans gaining insurance through exchange networks, this presents a major barrier to accessing optimal cancer care, especially as demand for these services continues to increase. These findings highlight the changing landscape of insurance, and the importance of continuing to evaluate the evolving network adequacy of the ACA exchanges.

\section{Disparities in Access: Impact on Survival}

When choosing a health plan, consumers may not be aware of in-network providers, nor the cost of seeing providers out-of-network. However, when diagnosed with cancer, patients want the highest-quality care to give them the best chance of survival. As evidenced in the Avalere and Avalere-NCCN surveys, exchange networks had $42 \%$ fewer oncology providers, and most of the NCI-designated centers that have exchange plans with tiered provider networks fall into the highest tier. ${ }^{16-18}$

In order to explore the impact of treatment site on survival along with access to specialized sites, Wolfson et $\mathrm{al}^{19}$ used population-level data in cancers common to adolescents and young adults (AYAs), evaluating NCI-designated comprehensive cancer centers (NCICCC) or Children's Oncology Group (COG) sites compared with other sites. To do this, they focused on nearly 103,000 children (aged 1-14 years), AYAs (15-39 years of age), and adults (4065 years of age) diagnosed between 1998 and 2008 in Los Angeles County (LAC) and reported to the LAC Cancer Registry. In patients with WHO grade II brain and spinal cord tumors, poor outcomes in AYAs compared with children were mitigated by receiving care at the $\mathrm{NCICCC}$ or COG site, with superior overall survival in NCICCC/COG patients. In those aged 21 years or younger, age alone impacted treatment site, whereas in those aged 22 to 39 years, socioeconomic status (SES), payer, and distance from the nearest specialized site all impacted where a patient received care.

In individuals aged 22 to 65 years with adultonset cancers common to AYAs (breast, colorectal, lung, hepatic, pancreatic, gastric), patients not treated at NCICCCs had a 20\% to 50\% higher risk of mortality compared with patients treated at NCICCCs, adjusting for stage, age, race/ethnicity, sex, SES, and payer; factors impacting the odds of receiving care at a specialized site included race/ethnicity, payer, SES, 
Value, Access, and Cost of Cancer Care

\begin{tabular}{|c|c|c|c|c|c|}
\hline \multirow[b]{2}{*}{ Primary Diagnosis } & & \multicolumn{2}{|l|}{ 5-Year OS } & \multicolumn{2}{|c|}{ Likelihood of Mortality } \\
\hline & & OS $(95 \% \mathrm{Cl})$ & $P$ Value & HR $(95 \% \mathrm{Cl})$ & $P$ Value \\
\hline \multicolumn{6}{|l|}{ Full cohort } \\
\hline & $\mathrm{NCICCC}$ & $64.3 \%(62.7 \%-65.8$ & $<.001$ & 1.0 & $<.001$ \\
\hline & Non-NCICCC & $60.7 \%(60.3 \%-61.1 \%)$ & & $1.3(1.2-1.3)$ & \\
\hline \multicolumn{6}{|l|}{ Hepatobiliary } \\
\hline & $\mathrm{NCICCC}$ & $33.8 \%(29.5 \%-38.0 \%)$ & $<.001$ & 1.0 & $<.001$ \\
\hline & Non-NCICCC & $18.7 \%(17.3 \%-20.2 \%)$ & & $1.5(1.3-1.7)$ & \\
\hline \multicolumn{6}{|l|}{ Lung } \\
\hline & $\mathrm{NCICCC}$ & $27.7 \%(23.3 \%-32.1 \%)$ & $<.001$ & 1.0 & $<.001$ \\
\hline & Non-NCICCC & $16.5 \%(15.7 \%-17.3 \%)$ & & $1.4(1.3-1.6)$ & \\
\hline \multicolumn{6}{|l|}{ Pancreas } \\
\hline & $\mathrm{NCICCC}$ & $12.5 \%(7.8 \%-17.3 \%)$ & $<.001$ & 1.0 & $<.001$ \\
\hline & Non-NCICCC & $6.2 \%(5.0 \%-7.4 \%)$ & & $1.5(1.3-1.7)$ & \\
\hline \multicolumn{6}{|l|}{ Gastric } \\
\hline & $\mathrm{NCICCC}$ & $30.7 \%(22.0 \%-39.4 \%)$ & .007 & 1.0 & .01 \\
\hline & Non-NCICCC & $22.2 \%(20.4 \%-24.0 \%)$ & & $1.3(1.1-1.7)$ & \\
\hline \multicolumn{6}{|l|}{ Breast $^{\mathrm{b}, \mathrm{c}}$} \\
\hline & $\mathrm{NCICCC}$ & $88.6 \%(87.0 \%-90.1 \%)$ & $<.001$ & 1.0 & $<.001$ \\
\hline & Non-NCICCC & $85.9 \%(85.5 \%-86.3 \%)$ & & $1.3(1.1-1.5)$ & \\
\hline \multicolumn{6}{|l|}{ Cervical' } \\
\hline & $\mathrm{NCICCC}$ & $76.9 \%(69.3 \%-84.4 \%)$ & .27 & 1.0 & .14 \\
\hline & Non-NCICCC & $73.3 \%(71.7 \%-74.9 \%)$ & & $1.3(0.9-1.9)$ & \\
\hline \multicolumn{6}{|l|}{ Oral } \\
\hline & $\mathrm{NCICCC}$ & $68.5 \%(62.3 \%-74.7 \%)$ & .009 & 1.0 & .09 \\
\hline & Non-NCICCC & $58.8 \%(56.2 \%-61.4 \%)$ & & $1.2(1.0-1.5)$ & \\
\hline \multicolumn{6}{|l|}{ Colorectal } \\
\hline & $\mathrm{NCICCC}$ & $62.8 \%(58.1 \%-67.5 \%)$ & .31 & 1.0 & .05 \\
\hline & Non-NCICCC & $62.6 \%(61.6 \%-63.5 \%)$ & & $1.2(1.0-1.4)$ & \\
\hline
\end{tabular}

Bold values indicate statistically significant findings.

Abbreviations: HR, hazard ratio; NCICCC, National Cancer Institute-Designated Comprehensive Cancer Center; OS, overall survival.

a Multivariable Cox regression analysis adjusted for age, sex, stage of disease, race/ethnicity, socioeconomic status, and payer. For full cohort, the model also adjusted for diagnosis.

${ }^{b}$ Adjusted for histology.

'Among women.

From Wolfson JA, Sun CL, Wyatt L, et al. Impact of care at comprehensive cancer centers on outcome: results from a population-based study. Cancer 2015;121:3885-3893; with permission.

and distance that a patient lived from the nearest specialized site (Table 1). ${ }^{20}$ Furthermore, Memorial Sloan Kettering Cancer Center used fee-for-service Medicare claims data and the SEER-Medicare database to show that patients treated at specialty cancer hospitals have a $10 \%$ lower chance of dying in the first year than those treated at community hospitals after adjusting for case mix. ${ }^{21}$

These studies provide evidence of better overall survival in patients receiving care at academic cancer centers. Nevertheless, such centers may fall into hightiered provider networks, be covered by only some exchange networks, or be offered in less common, more expensive PPO plans; this suggests that large segments of the population may be denied access to optimal care and outcomes as a result of financial barriers to accessing cancer care in the academic setting. The NCCN Work Group posits that employers require education to ensure that they offer plans that will help their employees receive optimal care with superior outcomes, 
and consumers require information regarding providers and networks in order to make informed coverage decisions based on individual needs. The NCCN Work Group also suggests educating and leveraging policymakers to ensure network adequacy language that allows patients to have access to subspecialty expertise at academic cancer centers. To this end, the NCCN Work Group recommends that (1) these specialized centers prioritize educating employers and consumers regarding the outcome advantages of treatment in the academic centers, (2) academic cancer centers continue to differentiate themselves in terms of specialists and specialty care, and (3) these specialized centers continue to disseminate information and educate consumers regarding the clinical value of academic cancer centers.

\section{The Value Proposition}

\section{Defining Value}

Value has often been understood as patient health outcomes achieved per dollar spent. ${ }^{22}$ However, these variables are currently at odds in cancer care, with an increasingly unsustainable cost of care and modest gains in health outcomes. In the setting of health care reform and a push for the oncology community to confront cost as a variable in care, defining how to measure value has become a priority. Health care reform calls for new models that shift to value-based payments; Michael Porter ${ }^{22}$ cites failure to measure value as one of the principal reasons why reform in health care has been so difficult compared with other fields. Defining, measuring, and delivering high-value care has been a key focus across the oncology community in recent years and will continue to lead health reform efforts.

Solutions for providing high-value care are perpetually in development, likely due to the lack of a universal definition of value. Lack of agreement from conflicting stakeholders, increasing costs, and modest gains in survival outcomes has led to a "value crisis" in oncology. ${ }^{23}$ It was further suggested at the NCCN Policy Summit that the gap between the understanding of value for patients and the understanding of value among physicians and the health system is one of the biggest barriers to patient-centered care. Patient-centered care is respectful of and responsive to individual patient preferences, needs, and values, and ensures that their values guide all clinical deci- sions. ${ }^{24}$ From the patient point of view, high-value care requires provider trust and transparency, care coordination, survivorship care, quality of life, mitigated disparities, toxicity management, limited travel for care, and limited financial risk. The Cancer Support Community's Cancer Experience Registry found that nearly $40 \%$ of the women with metastatic breast cancer defined value in terms of a "personal value," such as quality of life. ${ }^{25}$ On the other hand, only $7.4 \%$ of the women surveyed defined value in terms of an "exchange value," for whom $76 \%$ the most important element was the relationship with their health care provider. ${ }^{25}$

In this quest to define value, each entity differs on their focus. Figure 1 showcases the dynamic relationship in priorities as experienced by $3 \mathrm{com}$ ponents of cancer health care: patients, the health system, and the academic medical center/academic cancer center. ${ }^{26}$ Priorities for the health care system include provision of coordinated multidisciplinary care, subspecialists, novel agents, and equitable care along with the ability to bring in new technology. Academic medical centers focus on training the next generation of physicians and scientists, developing best practices, increasing efficiency, addressing issues of equitable care delivery, creating discovery and innovation, developing and leading basic and clinical research, and population health. When looking at the value equation, therefore, determining value may mean looking at access to care. Despite the dynamic tension of these perspectives, it is critical to recognize the perspectives of all stakeholders regarding the value proposition.

\section{Value of Academic Cancer Centers}

A common criticism of academic cancer centers argues that receiving care at such centers costs more. However, the studies performed by Wolfson et $\mathrm{al}^{19,20}$ and Memorial Sloan Kettering Cancer Center ${ }^{21}$ suggest that survival outcomes at these centers are superior. Thus, the NCCN Work Group recognizes the need for academic cancer centers to identify and quantify areas in which they provide unique contributions. $\mathrm{Nu}$ merous areas of expertise contribute to the value that these centers provide to both patients and the health care system. For example, academic cancer centers perform complicated surgeries at higher rates and experience better outcomes. ${ }^{27-30}$ Additionally, they offer improved multimodality treatment planning and delivery and multisite tissue acquisition. Furthermore, 
Value, Access, and Cost of Cancer Care

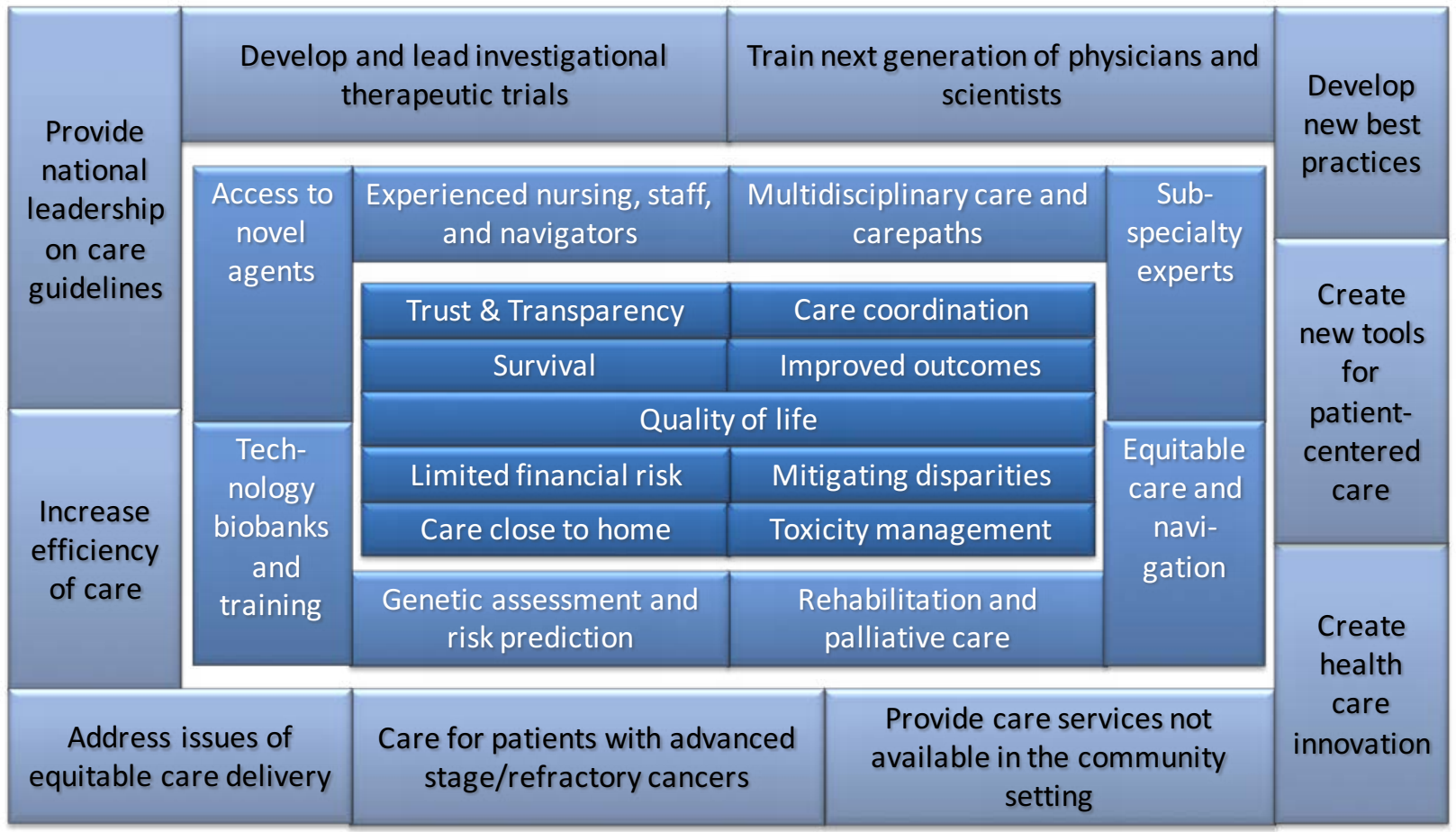

Figure 1. Linking value for patients, institutions, and centers.

pathology departments at academic cancer centers deliver highly accurate diagnoses of all types of cancer and provide support for complex patient care and stem cell transplantation. They also support broad research platforms, from all phases of clinical trials to basic and translational research. The University of Nebraska compared referral diagnosis and second review diagnosis for more than 1,000 lymphoma cases referred during 2009 through 2010; 15\% of the second reviews resulted in a major diagnostic change, of which $13 \%$ would have resulted in a therapeutic change. ${ }^{31}$ There were higher rates of major discrepancy in diagnoses from nonacademic centers (16\%) compared with academic centers (9\%). ${ }^{32}$ In addition to these attributes, distinguishing factors of the academic cancer centers are seen in Table 2. ${ }^{32}$ The NCCN Work Group believes these attributes should be a focus in defining the value of academic cancer centers.

Some suggest that academic cancer centers should not be evaluated on the same metrics as community hospitals. Nationally endorsed metrics devalue innovation, equitable care, novel therapeutics, expert services, teaching, and the development of novel practices; all of these are central to the mission of academic cancer centers and are often lacking in community settings. Existing quality metrics often fo- cus on process measures rather than on outcome measures, such as survival and progression-free survival, and risk-adjustment techniques are antiquated, which creates bias against academic centers that treat higher-risk patients. For these reasons, the NCCN Work Group recommends that academic centers establish metrics that are in alignment with the quality outcomes that matter to the centers, patients, employers, and payers. This requires high-quality data evaluating the long-term cost/benefit analysis. Academic cancer centers need to master their own data to be able to quantify value, especially as payment models continue to shift toward value-based delivery.

It is important to note, that not all patients with cancer can receive care at academic centers. The NCCN Work Group recognizes that it does not need to be a binary decision of a patient receiving care at either an academic center or a nonacademic center. To deliver the highest value care, the care must be integrated, coordinated, and patient-centered. Ideally, patients would receive the most appropriate care at the site that is most effectively aligned with their risk-based care needs while achieving the most meaningful outcomes at a sustainable cost. ${ }^{33}$ 
Nardi et al

\begin{tabular}{|ll|}
\hline Table 2. What Constitutes Health Care Value? & \\
\hline What Constitutes Health Care Value for a Community Hospital? & What Constitutes Health Care Value for an Academic Cancer Center? \\
\hline - Adequate access to care services & - Provide care services not available in community setting \\
- Good health care outcomes & - Care for patients with advanced stage/refractory cancers \\
- Low cost of care & - Develop and lead investigational therapeutic trials \\
- Best practice-based medicine & - Develop new best practices \\
- Sustainability of the health care system & - Provide national leadership on care guidelines \\
& - Create health care Innovation \\
& - Create new tools for patient-centered care \\
& - Address issues of equitable care delivery \\
& - Train next generation of physicians and scientists \\
\hline
\end{tabular}

From Alvarnas JA. Quality, value, innovation: developing a value proposition for care of patients with hematological malignancies. Presented at the NCCN Cancer Center Directors Meeting; April 13, 2015; Duarte, CA; with permission.

\section{Cost of Care}

Annual direct cost of cancer care in the United States for the most common cancers is estimated to be $\$ 124.6$ billion in 2010 US dollars ${ }^{34}$ and is expected to reach $\$ 173$ billion by $2020 .{ }^{34}$ Patients with cancer constitute $0.68 \%$ of the commercially insured population but account for $10 \%$ of health care costs incurred. ${ }^{35}$ Drivers of high costs can vary from drug prices to acute inpatient hospitalizations in the last months of life to high-cost imaging. Health care providers, payers, health systems, and cancer center administrators are stewards of highly expensive care, and these rising health care costs have implications for all. Payers are resorting to cost-cutting measures, such as tiered or narrow networks; patients are increasingly sharing the burden through higher premiums and/or out-of-pocket costs; and providers are shifting to value-based payment models that may apply a positive, negative, or neutral payment adjustment.

One particular driver of cancer care costs is cancer drug prices (Figure 2). ${ }^{36}$ Although 20 years ago paclitaxel (Taxol, Bristol-Myers Squibb, New York, NY) was the only commonly used cancer drug that cost more than $\$ 2,500$ a month, new FDA-approved cancer therapies today cost many times that amount, even priced at $\$ 10,000$ a month or more. ${ }^{36}$ Additionally, patients with cancer receiving chemotherapy incur nearly 4 times the per-person cost of patients with cancer not receiving chemotherapy, and account for more than $20 \%$ of the commercially insured. ${ }^{35}$ Drug costs burden patients and the system at large, yet containing them poses challenges and has become a target area for policy reform, even from presidential candidates.

Other drivers of high cancer care costs include acute hospital care, especially at the end of life. Brooks recently showed that acute hospital care was the largest component of spending for Medicare patients with advanced cancers, ${ }^{37}$ with nearly $50 \%$ for acute hospital care, followed by chemotherapy and oral drugs (16\% each) (Table 3). ${ }^{37}$ Furthermore, data suggest that cancer care in the last months of life account for a large proportion of the bill, with an increase from $\$ 7,834$ in the sixth month before death to more than $\$ 25,000$ in the last month of life. ${ }^{38}$ Inpatient care contributed most to these escalating costs; outpatient costs decreased and aggressive chemotherapy and novel targeted therapies represented smaller proportions of the bill..$^{38}$ Providers have the

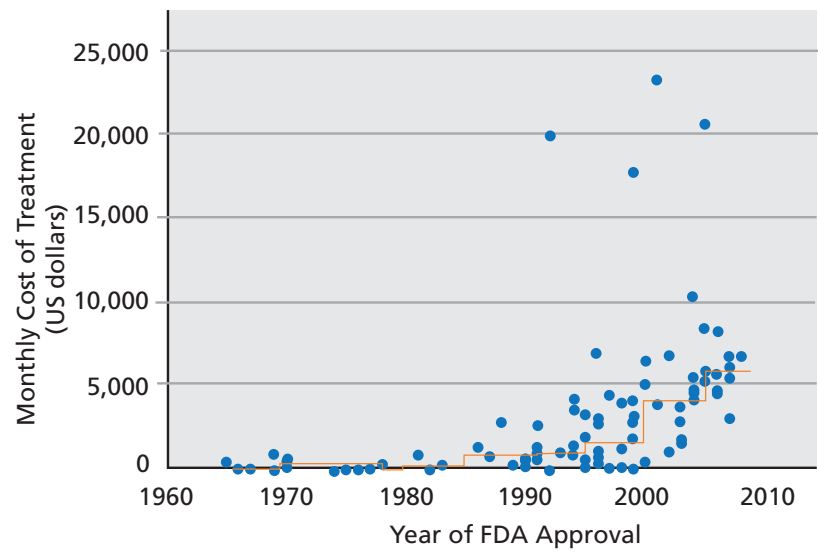

Figure 2. Monthly and median costs of cancer drugs at the time of approval by the FDA, from 1965 through 2008.

From Bach PB. Limits on Medicare's ability to control rising spending on cancer drugs. N Engl J Med 2009;360:626-633; with permission. 
Value, Access, and Cost of Cancer Care

Table 3. Spending Variation by Specific Advanced Cancer Service Categories

\begin{tabular}{|llr|}
\hline Service Category & Description & \multicolumn{2}{c}{$\begin{array}{l}\text { Mean 6-Month Spending, } \\
\text { 2011 \$US }\end{array}$} & 16,953 \\
\hline Acute hospital care & Acute hospital and inpatient physician services & 5,705 \\
\hline Chemotherapy & Intravenous and oral-equivalent chemotherapies & 2,281 \\
\hline Outpatient procedures & Outpatient surgery and other outpatient procedures & 1,837 \\
\hline Imaging & X-ray, ultrasound, CT, MRI, and nuclear medicine & 1,832 \\
\hline Radiation therapy & Radiation therapy & 1,743 \\
\hline Hospice & All hospice services & 870 \\
\hline Home health & Home care services, excluding hospice & 865 \\
\hline Outpatient physician services & Outpatient physician evaluation and management & 864 \\
\hline Diagnostics & Laboratory and pathology testing and evaluation & 804 \\
\hline Part B medications & Part B medications, excluding chemotherapy & 611 \\
\hline Postacute facility & Skilled nursing facilities and rehabilitation hospitals & 406 \\
\hline Other Part B & Ambulance, vision, and hearing services, etc. & 351 \\
\hline Durable medical equipment & Durable medical equipment for home use & 35,257 \\
\hline Total & All service categories & \\
\hline
\end{tabular}

From Brooks GA, Li L, Uno H, et al. Acute hospital care is the chief driver of regional spending variation in Medicare patients with advanced cancer. Health Aff (Millwood) 2014;33:1793-1800; with permission.

opportunity to address this cost issue by asking patients where they want their care at the end of life. Furthermore, advanced care planning avoids both the emotional and financial toxicities due to expenses associated with the final days or weeks of life. The hope is that with new reforms surrounding end-oflife care, costs will decrease.

The rising costs of cancer care are increasingly being shifted to patients through premium increases, high deductibles, and copays. Premiums and out of pocket health care costs for a family are projected to equal half the median household income by 2018 and the entire income by $2030 .{ }^{39}$ Further, for patients with copays of $20 \%$ to $30 \%$, the math becomes catastrophic, unsustainable, and limits access. Financial toxicity, which refers to the unintended financial consequences of patients embracing expensive treatments, has an increasing burden on patients. ${ }^{40}$ Duke University and Dana-Farber Cancer Institute reported that $42 \%$ of patients perceived a significant or catastrophic subjective financial burden due to out-of-pocket expenses (average $\$ 1,266 /$ month), $46 \%$ used all or part of their savings, and slightly less than half borrowed money to pay for prescriptions. ${ }^{41}$ Importantly, these expenses impacted medication adherence: 20\% reported taking less than the prescribed amount of medication, $19 \%$ filled only part of a prescription, and
$24 \%$ avoided filling prescriptions at all. ${ }^{41}$ Similarly, Cancer Support Community showed a significant linear increase in overall distress and risk for depression in patients with myeloma associated with greater monthly out-of-pocket costs, adjusting for income. ${ }^{42}$ Nearly one-third of patients experienced clinically high levels of stress-related anxiety about the financial cost of care, whereas 33\% reported being often or always upset about money and the cost of care, and $47 \%$ were moderately, seriously, or very seriously concerned about health insurance or money worries. ${ }^{42}$ High costs have both financial and clinical implications for patient care.

Payment reform provides additional opportunity for cost control while remaining focused on quality. Examples include medical homes, bundled payments, and accountable care organizations.

- Medical homes for specialties support care coordination, prevention, and disease management, while rewarding reductions in oncology care-related costs.

- Bundled payments combine payments for specific episodes across providers and settings, promoting coordination and efficiency, and linking to quality measurements to support accountability.

- Accountable care or system-wide efforts reimburse population-level improvements in quality and overall per-capita costs, encouraging communica- 
tion across the continuum of care, reinforcing and supporting cohesive accountable-care reforms.

Both academic and community settings play a role in the transition to these models. The NCCN Work Group recommends discussion regarding the components of each of these constructs in order to collaborate across systems and achieve value-driven care.

The NCCN Work Group also recommends that academic cancer centers focus on managing utilization and becoming efficient stewards of high-cost services, procedures, and products that are so vitally important for patients with cancer and their families to maximize survival and quality of life. Areas of opportunities for targeted cost-control measures include high-cost treatments, high-cost radiation therapy, molecular diagnostics, high-cost imaging, potentially avoidable hospitalizations, emergency room utilization, and end-of-life care. ${ }^{43}$

UC San Diego Moores Cancer Center provides an example of an academic center pursuing several initiatives that may impact costs. ${ }^{43}$ To minimize potentially avoidable hospitalizations, providers are asked to call to patients after discharge, focus on transitions of care, provide access for urgent appointments, and provide distress screening and psychosocial interventions. Emergency room utilization may be mitigated with extended infusion center hours and with plans for a same-day service. Planned endof-life care initiatives that are more patient-centered and lower in costs include clinic-dedicated social workers for early advanced care planning, and designated electronic medical record section and tools for documentation of advanced care planning goals.

Although it is generally assumed that academic cancer centers have higher costs, the NCCN Work Group recommends academic cancer centers strive to demonstrate the extra value they provide. These higher costs are related to state-of-the-art technology, expert surgery, oncology radiation, pathology, radiology, tumor boards, integrated subspecialty multidisciplinary care, novel therapeutics and clinical trials, experienced nursing, support staff, rehabilitation services, genetic risk assessment for early detection, the learning and discovery environment, care for the underinsured, and palliative care services. Developing a value statement of these centers that highlight the added value that they offer through multidisciplinary care, clinical trial access, novel therapeutics, and more is one recommendation of the NCCN Work Group. Moreover, academic cancer centers should take a larger role in defining and addressing cost, develop tools for patient-centered outcomes that matter to patients, develop tools for patient-centered cost discussions, capture outcomes and costs during routine care, create a learning environment from cost and outcome data, and develop and participate in innovative models for managing utilization and choosing high-cost services.

\section{Conclusions}

Challenges persist to accessing cancer care at, defining value of, and lowering costs at academic cancer centers. Academic cancer centers have shown superior survival outcomes compared with community settings; continuing to exemplify value through high-quality data can help to explain higher costs at academic cancer centers. Additionally, network adequacy that allows patients to access care at academic cancer centers contributes to high-value care. The NCCN Work Group recommends initiatives for academic cancer centers to remain leaders amidst the quickly changing oncology landscape: educating consumers, payers, and employers on the value of the centers; continuing to master and produce data that quantifies areas where they perform better; exploring opportunities for cost control while maintaining quality; demonstrating extra value for higher cost; and continuing to be leaders of cancer care by providing high-quality cancer care.

\section{References}

1. American Society of Clinical Oncology. The state of cancer care in America, 2015: a report by the American Society of Clinical Oncology. J Oncol Pract 2015;11:79-113.

2. Cooper Z, Craig SV, Gaynor M, et al. The Price Ain't Right? Hospital Prices and Health Spending on the Privately Insured. NBER Working Paper No. 21815 Issued in December 2015. Available at: http://www.nber. org/papers/w21815. Accessed March 1, 2016.

3. Cox C, Gonzales S, Kamal R, et al. Analysis of 2016 Premium Changes in the Affordable Care Act's Health Insurance Marketplaces. Kaiser Family Foundation Web site. Available at: http://kff.org/health-reform/fact-sheet/ analysis-of-2016-premium-changes-in-the-affordable-care-acts-healthinsurance-marketplaces/. Accessed March 1, 2016.

4. Glick S, Gandhi N. Surviving and Thriving in the New Commercial Environment. Available at: http://www.americangovernance.com/ education/symposia/2015/winter/files/feb15glick-gandhi.pdf. Accessed March 1, 2016.

5. Mathews AW, Armour S. Biggest Insurer Threatens to Abandon Health Law. Wall Street Journal. November 19, 2015. Available at: http://www. wsj.com/articles/unitedhealth-cuts-guidance-evaluating-its-insuranceexchange-segment-1447933310. Accessed March 1, 2016. 
Value, Access, and Cost of Cancer Care

6. Mathews AW. Regulators to Shut Down Health Republic Insurance of New York. Wall Street Journal. September 25, 2015. Available at: http:// www.wsj.com/articles/regulators-to-shut-down-health-republic-insuranceof-new-york-1443222742. Accessed March 1, 2016.

7. Campanile C. ObamaCare Leaves 250 Cancer Patients in Peril. New York Post. November 6, 2015. Available at: http://nypost.com/2015/11/06/ obamacare-leaves-250-cancer-patients-in-peril/. Accessed March 1, 2016.

8. Newsroom: Modest Health Benefit Cost Growth Continues as Consumerism Kicks Into High Gear. Mercer Web site. November 19 2014. Available at: http://www.mercer.com/newsroom/modest-healthbenefit-cost-growth-continues-as-consumerism-kicks-into-high-gear-html. Accessed March 1, 2016.

9. Newcomer L. Staying Relevant for the Consumer. UnitedHealthcare. Presented at the NCCN Cancer Center Directors Meeting; April 13, 2015 Duarte, CA.

10. 2015 Employer Health Benefits Survey. The Henry J. Kaiser Family Foundation Web site. September 22, 2015. Available at: http://kff.org/ report-section/ehbs-2015-summary-of-findings/. Accessed March 1, 2016.

11. Milliman. Milliman Report: High-Value Healthcare Provider Networks AHIP Web site. July 1, 2014. Available at: http://www.ahip.org/ MillimanReportHPN2014/. Accessed March 1, 2016.

12. Andrews M. Warning: Opting Out of Your Insurance Plan's Provider Network is Risky. Kaiser Health News Web site. Available at: http://khn org/news/michelle-andrews-opting-out-insurer-provider-network-risky/. Accessed March 1, 2016

13. Avalere Health LLC. Network Design: Trends in Tiered and Narrow Insurance Networks. October 2015. Available at: https://www. whathealthcarecostsnj.com/wp-content/uploads/2015/10/AvalereWhitepaper.pdf. Accessed March 1, 2016.

14. Hempstead K. Burnt Offerings? PPOs DECLINE in Marketplace Plans. Robert Wood Johnson Foundation Web site. Available at: http://www.rwjf. org/en/library/research/2015/10/decline-in-ppo-offerings-in-marketplaceplans-in-2016.html. Accessed March 1, 2016

15. Appleby J, Rau J. As HMOs Dominate, Alternatives Become More Expensive. Kaiser Health News Web site. Available at: http://khn.org/ news/as-hmos-dominate-alternatives-become-more-expensive/. Accessed March 1, 2016.

16. Pearson CF, Choe SH. Leading Cancer Centers May Be More Widely Included in Exchange Networks Than Expected. Avalere Health Web site. Available at: http://avalere.com/expertise/life-sciences/insights/leadingcancer-centers-may-be-more-widely-included-in-exchange-networks-tha. Accessed March 1, 2016

17. Diasio R. NCCN Work Group Report on Access to Academic Cancer Centers. Presented at the NCCN Policy Summit: Value, Access, and Cost of Cancer Care Policy Summit; September 11, 2015; Washington, DC.

18. Sloan C, Carpenter E. Exchange Plans Include 34 Percent Fewer Providers than the Average for Commercial Plans. Avalere Health Web site. Available at: http://avalere.com/expertise/managed-care/insights/ exchange-plans-include-34-percent-fewer-providers-than-the-average-forcomm. Accessed March 12016.

19. Wolfson J, Sun CL, Kang T, et al. Impact of treatment site in adolescents and young adults with central nervous system tumors. J Natl Cancer Inst 2014;106:dju166

20. Wolfson JA, Sun CL, Wyatt L, et al. Impact of care at comprehensive cancer centers on outcome: results from a population-based study. Cancer 2015;121:3885-3893

21. Pfister DG, Rubin DM, Elkin EB, et al. Risk adjusting survival outcomes in hospitals that treat patients with cancer without information on cancer stage. JAMA Oncol 2015;1:1303-1310.

22. Porter ME. What is value in health care? N Engl J Med 2010;363:2477248
23. Ramsey S, Schickendanz A. How should we define value in cancer care? Oncologist 2010;15(Suppl 1):1-4.

24. Institute of Medicine. Crossing the Quality Chasm: A New Health System for the 21st Century. Washington, DC: National Academy Press; 2001

25. Longacre ML, Charap ES, Buzaglo JS, et al. Defining value in oncology: perspectives from patients with metastatic breast cancer. cancer support community. Presented at the Association for Value-Based Cancer Care, 5th Annual Conference; May 3-6, 2015; Washington, DC.

26. Gerson S. NCCN Work Group Report on Value of Academic Cancer Centers. Presented at the NCCN Policy Summit: Value, Access, and Cost of Cancer Care Policy Summit; September 11, 2015; Washington, DC.

27. Gordon TA, Burleyson GP, Tielsch JM, et al. The effects of regionalization on cost and outcome for one general high-risk surgical procedure. Ann Surg 1995;221:43-49.

28. Choti MA, Bowman HM, Pitt HA, et al. Should hepatic resections be performed at high-volume referral centers? J Gastrointest Surg 1998;2:1120.

29. Fong Y, Gonen M, Rubin D, et al. Long-term survival is superior after resection for cancer in high-volume centers. Ann Surg 2005:242:540-544.

30. Begg CB, Cramer LD, Hoskins WJ, et al. Impact of hospital volume on operative mortality for major cancer surgery. JAMA 1998;280:1747-1751.

31. Bowen JM, Perry AM, Laurini JA, et al. Lymphoma diagnosis at an academic centre: rate of revision and impact on patient care. Br J Haematol 2014;166:202-208

32. Alvarnas JA. Quality, value, innovation: developing a value proposition for care of patients with hematological malignancies. Presented at the NCCN Cancer Center Directors Meeting; April 13, 2015; Duarte, CA.

33. Alvarnas J, Majkowski GR, Levine AM. Moving toward economically sustainable value-based cancer care in the academic setting. JAMA Oncol 2015;1:1221-1222.

34. Mariotto AB, Yabroff KR, Shao $\mathrm{Y}$, et al. Projections of the cost of cancer care in the United States: 2010-2020. J Natl Cancer Inst 2011;103:117128.

35. Fitch K, Pyensin B. Cancer Patients Receiving Chemotherapy: Opportunities for Better Management. Milliman, Inc. Available at: http:// www.milliman.com/uploadedFiles/insight/research/health-rr/cancerpatients-receiving-chemotherapy.pdf. Accessed March 1, 2016.

36. Bach, Peter B. Limits on Medicare's ability to control rising spending on cancer drugs, N Engl J Med 2009;360:626-633.

37. Brooks GA, Li L, Uno H, et al. Acute hospital care is the chief driver of regional spending variation in medicare patients with advanced cancer. Health Affairs 2014;33:1793-1800.

38. VBCC. The Big Cost Drivers in End-of-Life Cancer Care Are Not the Drugs. June 2011, Volume 2, No 3. Available at: http://www. valuebasedcancer.com/vbcc-issues/2011/june-2011-vol-2-no-3/558vbcc-558. Accessed June 20, 2016.

39. Young RA, DeVoe JE. Who will have health insurance in the future? An updated projection. Ann Fam Med 2012;10:156-162.

40. Zafar SY, Abernethy AP. Financial toxicity, part I: a new name for a growing problem. Oncology (Williston Park) 2013;27:80-149.

41. Zafar Y, Peppercorn JM, Schrag D, et al. The financial toxicity of cancer treatment: a pilot study assessing out-of-pocket expenses and the insured cancer patient's experience. Oncologist 2013;18:381-390.

42. Buzaglo JS, Miller MF, Karten C, et al. Multiple myeloma patient experience with financial toxicity: findings from the Cancer Experience Registry. Presented at the ASH 57th Annual Meeting and Exposition; December 5-8, 2015; Orlando, FL.

43. Parker B. NCCN Work Group Report on Cost of Cancer Care. Presented at the NCCN Policy Summit: Value, Access, and Cost of Cancer Care Policy Summit; September 11, 2015; Washington, DC. 